\title{
Effectiveness of Structured Teaching Programme on Knowledge of Preparation and Management of Labour among Primigravida Women in Selected Hospital, Salem, Tamilnadu, India
}

\section{Santhi}

Jazan University, Ministry of Higher Education, Kingdom of Saudi Arabia

Corresponding Author: Santhi, Jazan University, Ministry of Higher Education, Kingdom of Saudi Arabia

Received date: February 17, 2020; Accepted date: March 06, 2020; Published date: March $16,2020$.

Citation: Santhi, (2020) Effectiveness of Structured Teaching Programme On Knowledge Of Preparation And Management Of Labour Among Primigravida Women In Selected Hospital, Salem, Tamilnadu, India, 3(1): Doi: 10.31579/2692-9422/006

Copyright: () 2020 Santhi, This is an open-access article distributed under the terms of The Creative Commons Attribution License, which permits unrestricted use, distribution, and reproduction in any medium, provided the original author and source are credited.

\begin{abstract}
:
Labor is one of the most painful events in a women's life. Many women would like to avoid pharmacological or invasive methods of pain management in labour, and this may contribute towards the popularity of complementary methods of pain management. This review examined the evidence currently available on manual methods, including frequent change in positions, massage and reflexology, for pain management in labour. The main aim of this study is to identify the level of knowledge on preparation and management of labour among primigravida women. A pre experimental one group pre and post test design was selected and adapted purposive sampling technique to recruit the samples. The total sample size was 30 . Tools used like demographic variables, structured interview schedule and structured teaching programme on preparation and management of labour. At the first day, pre test was conducted by using SIS and structured teaching on preparation and management of labour was administered as a group of antenatal women. After 7 days post test was conducted by using same tool. Data analysis was done by descriptive and inferential statistics. Highest percentage $(50 \%)$ of the women were in the age group of 21-25 years. The overall mean score in pre test was $12.16 \pm 4.4$ and the mean percentage 40.53 where as in post test the overall mean score was $22.76 \pm 7.26$ and the mean percentage was 75.87 . The calculated 't' value was 10.18 at 0.05 level of significance. It depicts that structured teaching prgramme on preparation and management of labour was highly effective. There was no significant association between the demographic variables with pre and post test knowledge scores.
\end{abstract}

Keywords: preparation and management of labour, structured teaching programme, primigravida women.

\section{Introduction:}

Labor is the process through which a fetus and placenta are delivered from the uterus through the vagina. Human labor divides into three stages. The first stage is further divided into two phases. Successful labor involves three factors, which include maternal efforts and uterine contractions, fetal characteristics, and pelvic anatomy. This

triad is classically referred to as the passenger, power, and

passage. Labor is typically monitored by multiple modalities. Serial cervical examinations are used to determine cervical dilation, effacement, and fetal position, also known as the station. Fetal heart monitoring is employed nearly continuously to asses fetal well-being throughout labor.

Making use of good, evidence based routines, for management of normal childbirth is essential to ensure quality of care and prevent, identify and manage complications if they occur. Two essential routine care interventions as defined by the World Health Organization are the use of the Partograph and Active Management of the Third Stage of Labour. Both interventions have been evaluated for their ability to assist health providers to detect and deal with complications.

A study conducted on Effectiveness of pharmacological and non-pharmacological pain relief methods and to compare them. 258 women were included in the study and interviewed using a questionnaire and the visual analogue scale for pain. They were divided into six groups depending on chosen method of labour pain relief: epidural anaesthesia (EA; $n=42)$, water immersion and water birth (WB; $n=40)$, nitrous oxide gas for pain control $(\mathrm{G} ; n=40)$, transcutaneous electrical nerve stimulation (TENS) $(n=50)$, multiple management $(\mathrm{MM} ; n=42)$, none $(\mathrm{N} ; n=44)$. The average age of the women was $29.4 \pm 3.74$ years and $60.47 \%$ of them were nulliparous $(n=156)$. Mean values of labour pain intensity were $6.81 \pm 2.26$ during the first stage of labour; $7.86 \pm 2.06$ during the second stage, and $3.22 \pm 2.46$ during the third stage. There was no significant difference in pain level between epidural analgesia and gas groups in the first stage of labour $(p=0.74)$. Nevertheless, epidural analgesia reduced pain level during the second and third stage (both $p<$ $0.01)$. The highest satisfaction level pertains to water immersion $(n=38$; $95 \%$ ). Epidural analgesia is the gold standard of labour pain relief, however water birth was found to be associated with the highest satisfaction level of the parturient women.

Conducted a retrospective cohort study of 264 singleton pregnancies during labor was performed at a low-risk pregnancy maternity during a 6-month period. Perineal trauma was classified according to the Royal College of Obstetricians and Gynecologists (RCOG). From a total of 264 women, there were 2 cases $(0.75 \%)$ of severe perineal trauma, which occurred in nulliparous women younger than 25 years old. Approximately $46 \%$ (121) of the women had no tears, and $7.95 \%$ (21) performed mediolateral episiotomies. Perineal trauma was not associated with maternal position $(p=0.285)$, health professional (obstetricians or midwives; $p=0.231$ ), newborns with 4 kilos or more $(p=0.672)$, and labor analgesia $(p=0.319)$. The multinomial analysis showed that white and nulliparous presented, respectively, 3.90 and 2.90 times more risk of presenting perineal tears. The incidence of severe 
perineal trauma was low. The prevalence of upright position during the second stage of labor was $42 \%$. White and nulliparous women were more prone to develop perineal tears.

Conducted a quasi-experimental study. Eighty women were interviewed as a study sample when admitted to the labor and delivery area and divided into three groups: 20 women received frequent changes in position (group A), 20 women received back massage (Group B), and 40 women constituted the control group (group C). Pain perception was measured after each intervention using the Face Pain Scale. The mean rank of the difference in pain scores among the study groups was as follows after the first, second, and third interventions, respectively: group A-52.33, 47.00, 49.2; group B-32.8, 30.28, 30.38; group C-38.44, 42.36, 41.21. There were significant differences between groups $\mathrm{A}, \mathrm{B}$, and $\mathrm{C}$ after the first, second, and third interventions $\left(\mathrm{p}_{1}=.011, \mathrm{p}_{2}=.042\right.$, $\left.\mathrm{p}_{3}=.024\right)$. Back massage may be a more effectivepain management approach than change in position during the first stage of labor.

Randomised controlled trials comparing manual methods with standard care, other non-pharmacological forms ofpain management in labour, no treatment or placebo. We searched for trials of the following modalities: massage, warm packs, thermal manualmethods, reflexology, chiropractic, osteopathy, musculo-skeletal manipulation, deep tissue massage, neuro-muscular therapy, shiatsu, tuina, trigger point therapy, myotherapy and zero balancing. We excluded trials for pain management relating to hypnosis, aromatherapy, acupuncture and acupressure; these are included in other Cochrane reviews. Massage, warm pack and thermal manual methods may have a role in reducing pain, reducing length of labour and improving women's sense of control and emotional experience of labour, although the qualityof evidence varies from low to very low and few trials reported on the keyGRADE outcomes.

Conducted an observational and analytical retrospective cohort study conducted at the Mancha-Centro Hospital during the 2010-2014 period. Data were collected from 2990 women who gave birth vaginally. The main outcome variable was postpartum anaemia for two cut-off points (haemoglobin $(\mathrm{Hb})<11 \mathrm{~g} / \mathrm{dL}$ and $<9 \mathrm{~g} / \mathrm{dL}$ at $24-\mathrm{h}$ postpartum). Women with prepartum anaemia $(<11 \mathrm{~g} / \mathrm{dL})$ were excluded. It included a multivariate analysis by multiple linear regression. $45 \%$ (1341) of women had postpartum levels of $\mathrm{Hb}<11 \mathrm{~g} / \mathrm{dL}$, and $7.1 \%$ (212) of women had $\mathrm{Hb}$ $<9 \mathrm{~g} / \mathrm{dL}$. The most strongly associated risk factors with more severe anaemia $(\mathrm{Hb}<9 \mathrm{~g} / \mathrm{dL})$ were episiotomy (OR 3.19. 95\%CI: 2.10-4.84), first stage of labour $>9$ h (OR 2.50. 95\%CI: 1.58-3.94), primiparity(OR 2.50. 95\% CI: 1.61-3.87) and previous caesarean section (OR 2.43. 95\% CI: 1.51-3.90). The other independent risk factors for both Hb cutoff points were prolonged second stage of labour, instrumental birth, tearing>first degree, non-practice of active management and heavier birth weight of newborns. Postpartum anaemia has a high incidence. The active management of third stage of labour, selective practice of episiotomies, and performing instrumental births only when strictly necessary are efficient measures to lower the incidence of postpartum anaemia.

Acupuncture use in obstetrics has been increasing in Western medicine, especially to alleviate complications of pregnancy, the most important cause of maternal mortality worldwide. One quarter of maternal deaths are caused by complications in the third stage of labor, an interval between complete delivery of the baby and the complete expulsion of the placenta. Passive (or expectant) management ofthe third stage of labor is occasionally associated with massive obstetric hemorrhage, a major cause of maternal morbidity and mortality, especially in low-income countries. Active management of the third stage of labor has been shown to reduce the risk of postpartum hemorrhage. Use of acupuncture in the first and second stagesof labor could lead to a faster separation of the placenta in the third stage of labor. The possible effects of acupuncture in cases of retained placentas may have significant implications for possible complications and final outcomes of labor. Further studies are needed for more conclusive results.

A study conducted to assess the risks and benefits of squatting position during second stage of labour and its comparison with the supine position. There was no difference in the application of episiotomies in both groups, however extension of the episiotomy occurred in $7 \%$ patients of the non-squatting group $(\mathrm{P}<0.05)$. Para urethral tears occurred in 5\% patients in squatting group, but all occurred in patients who were not given an episiotomy. Second degree, and third degree perineal tears occurred in 9\% patients in the non-squatting group but none in the squatting group (P $<0.05$ ). Forceps application was also significantly lessin group-A $11 \%$ and $24 \%$ in group-B $(\mathrm{P}<0.05)$. There were two cases ofshoulder dystocia in group B but none in the group-A. During the Third stage of labour there were no cases of retained placenta in group A but there were $4 \%$ cases of retained placenta and $1 \%$ case of postpartum haemorrhage of more than $500 \mathrm{ml}$ due to atony of the uterus in group-B. One patient in the nonsquatting position had to have a caesarean section due to persistent occipito posterior position. There was no significant difference in the apgar scores, foetal heart rate patterns or requirement of neonatal resuscitation. It appears that squatting position may result in less instrumental deliveries, extension of episiotomies and perineal tears.

\section{Statement of the problem:}

A study to assess the Effectiveness of Structured Teaching Programme (STP) on Knowledge of Preparation and Management about Labour among Primigravida Women.

\section{Objectives:}

1. Assess the knowledge on preparation and management of labour among primigravida women before implementation education programme.

2. To evaluate the effectiveness of structured teaching programme on knowledge of preparation and management about labour.

3. To associate the pre and posttest knowledge scores of primigravida women with their selected demographic variables.

\section{Hypothesis:}

H1: There is a significant difference between pre and posttest knowledge scores on preparation and management of labour among primigravida women at $\mathrm{p} \leq 0.05$ level.

$\mathrm{H} 2$ : There is a significant association between the pre and posttest knowledge scores with the selected demographic variables at $\mathrm{p} \leq 0.05$ level.

\section{Conceptual framework:}

Adopted Rosenstock's and Becker Health Belief Model theory as a basis of conceptual framework, which is aimed to assess the effectiveness of structured teaching programme on knowledge of preparation and management of labour among primigravida women.

\section{Methods:}

Pre experimental one group pre and posttest research design was used. To recruit the samples Purposive sampling technique was used. The study was conducted in Private Hospital, Salem. 30 primigravida women who have $36 \& 37$ weeks of gestation visited in OPD of Private Hospital was selected as samples. Tools used like demographic variables, structured 
interview schedule and structured teaching programme on preparation and management of labour. At the first day, pre test was conducted by using SIS and structured teaching on preparation and management of labour was administered $20 \mathrm{mts}$ as a group of antenatal women (4-5 mothers). After 7 days post test was conducted by using same tool. Data analysis was done by descriptive and inferential statistics. Descriptive statistics like mean, standard deviation and mean percentage was used toassess the knowledge on preparation and management of labour pain. Inferential statistics like paired ' $t$ ' test was used to assess the difference between pre and post test knowledge scores. Chi square was used to assessthe association between pre and post test knowledge scores with selected demographic variables.

\section{Results:}

Highest percentage (50\%) of women were in the age group of 21-25 years. Maximum (70) were had higher education. Most of them (67\%) belong to Hindus and half of the percentage (54\%) were housewife. Majority of (53.3\%) women were having family monthly income of Rs. 5001-10,000 and both half of the percentage $(53.3 \%)$ of women belongs to nuclear family and labour support through her mother and all of them had regular antenatal check up (53\%)

\begin{tabular}{|l|c|c|c|c|}
\hline \multirow{2}{*}{ Level of Knowledge } & \multicolumn{2}{c|}{ Pre - test } & \multicolumn{2}{c|}{ Post - test } \\
\cline { 2 - 5 } & F & \% & F & \% \\
\hline Inadequate knowledge (1 - 33) & 18 & 56 & - & - \\
\hline Moderately adequate knowledge (34 - 66) & 12 & 44 & 6 & 12 \\
\hline Adequate knowledge (67 - 100) & - & - & 24 & 88 \\
\hline
\end{tabular}

Table No.1: Distribution of pre and post test level of knowledge scores on preparation and management of labour among primigravida women

Distribution of pre and posttest level of knowledge scores of preparation and management of labour among primigravida women shows that in pre test, 56 percentage of women had inadequate knowledge, where as in post test none of them had inadequate knowledge. In pre test in moderately adequate knowledge 44 percentage of them obtained information and where as in post test only 12 percentage of them obtained moderately adequate knowledge. In post test maximum $(88 \%)$ of the mothers had adequate knowledge and in pre test none of them obtained adequate knowledge. Hence it shows that after implementation of Structured Teaching Programme on preparation and management of labour mothers gained adequate knowledge so it was highly effective.

\begin{tabular}{|c|c|c|c|c|c|c|c|c|c|}
\hline \multirow{2}{*}{$\begin{array}{l}\text { S. } \\
\text { No }\end{array}$} & \multirow[b]{2}{*}{$\begin{array}{l}\text { Areas of preparation and } \\
\text { management of labour }\end{array}$} & \multirow{2}{*}{$\begin{array}{l}\text { Max } \\
\text { Score }\end{array}$} & \multicolumn{3}{|c|}{ Pre test } & \multicolumn{3}{|c|}{ Post test } & \multirow{2}{*}{$\begin{array}{l}\text { Diff. in } \\
\text { Mean \% }\end{array}$} \\
\hline & & & Mean & SD & $\begin{array}{l}\text { Mean } \\
\%\end{array}$ & Mean & SD & $\begin{array}{l}\text { Mean } \\
\%\end{array}$ & \\
\hline 1. & Introduction & 5 & 1.1 & 2.6 & 22 & 2.3 & 4.9 & 46 & 24 \\
\hline 2. & $\begin{array}{l}1^{\text {st }} \text { stage of labour symptoms \& } \\
\text { management }\end{array}$ & 10 & 4.2 & 5.2 & 42 & 5.3 & 6.3 & 53 & 11 \\
\hline 3. & $\begin{array}{l}2^{\text {nd }} \text { stage of labour symptoms and } \\
\text { management }\end{array}$ & 6 & 2.5 & 4.3 & 41 & 3.2 & 5.9 & 53 & 12 \\
\hline 4. & $\begin{array}{l}3^{\text {rd }} \text { stage of labour symptoms and } \\
\text { management }\end{array}$ & 6 & 2.7 & 5.1 & 45 & 3.2 & 5.9 & 53 & 8 \\
\hline 5. & $\begin{array}{c}4^{\text {th }} \text { stage of labour symptoms and } \\
\text { management }\end{array}$ & 3 & 1.5 & 4.3 & 50 & 1.9 & 5.4 & 63 & 13 \\
\hline & Total & 30 & 12 & 21.5 & 40 & 15.9 & 28.4 & 53 & 14 \\
\hline
\end{tabular}

Table No.2: Area wise distribution of mean, standard deviation and mean percentage on knowledge regarding preparation and management of labour among primigravida women

According to Area wise distribution of pre and post test knowledge scores shows that the highest mean score in both pre and post test was persist on the $4^{\text {th }}$ stage of labour symptoms and management which was $1.5 \pm 4.3$ and $1.9 \pm 5.4$, the mean percentage was $50 \%$ and $63 \%$ respectively. The lowest mean score was in both pre and post test which was $1.1 \pm 2.6$ and 2.3 \pm 4.9 , the mean percentage was $22 \%$ and $24 \%$ in the area of introduction. Hence it shows that after implementation of Structured Teaching Programme on preparation and management of labour was very much effective and highly significant.

\begin{tabular}{|c|c|c|c|c|c|c|}
\hline S.No & Knowledge & Max. Score & Mean & SD & $\begin{array}{c}\text { Mean } \\
\%\end{array}$ & 't' Value \\
\cline { 1 - 5 } & Pre -test & \multirow{2}{*}{30} & 12.16 & 4.4 & 40.53 & \multirow{2}{*}{$10.18^{*}$} \\
\hline 2. & Post-test & & 22.76 & 7.26 & 75.87 & \\
\hline
\end{tabular}

Table No.3: Assess the difference between mean, SD and ' $\mathrm{t}$ ' value of pre and post test knowledge scores on preparation and management of labour $\mathrm{df}=29 ; \mathrm{P}<0.05-$ Significant*

The Difference between mean, SD and paired ' $t$ ' test of pre and post test knowledge shows that in pre test, the overall mean score was $12.16 \pm 4.4$ Auctores Publishing - Volume 3(1)-006 www.auctoresonline.org 
was 10.18 at $\mathrm{p}<0.05$ level of significance, which shows it is highly significant. Hence it is interpreted that implementation of structured teaching programme was highly effective in improving the knowledge of primigravida women.

\begin{tabular}{|c|l|c|c|c|}
\hline S.No & \multicolumn{1}{|c|}{ Demographic varibles } & df & $\chi^{\mathbf{2}}$ & Table value \\
\hline 1 & Age in years & 6 & 4.204 & 12.59 \\
\hline 2 & Education & 8 & 1.518 & 15.51 \\
\hline 3 & Occupation & 6 & 1.081 & 12.59 \\
\hline 4 & Religion & 6 & 3.965 & 12.59 \\
\hline 5 & Type of family & 6 & 0.566 & 12.59 \\
\hline 6 & Monthly Income & 6 & 0.529 & 12.59 \\
\hline 7 & Weeks of gestation & 4 & 0.529 & 8.79 \\
\hline 8 & Labour support given by others & 6 & 3.309 & 12.59 \\
\hline 9 & Residence & 2 & 1.428 & 5.99 \\
\hline 10 & Antenatal checkup & 2 & 0 & 5.99 \\
\hline 11 & Previous hospitalization & 2 & 0.017 & \\
\hline
\end{tabular}

Table No. 4: Association between pretest knowledge scores of preparation and management of labour with their selected demographic variables df $=$ 29; $\mathrm{P}<0.05$ - Not Significant

There was no significant association between age, education, occupation, religion, type of family, weeks of gestation, monthly income, labour support given by others, residence, antenatal checkup, previous hospitalization with the pre test scores on preparation and management of labour. Hence it shows that the difference observed mean score values were not true difference so the research hypothesis was rejected.

\section{Conclusion:}

Highest percentage (50\%) of the women were in the age group of 21-25 years. The overall mean score in pre test was $12.16 \pm 4.4$ and the mean percentage 40.53 where as in post test the overall mean score was $22.76 \pm 7.26$ and the mean percentage was 75.87 . The calculated ' $t$ ' value was 10.18 at 0.05 level of significance. It depicts that structured teaching prgramme on preparation and management of labour was highly effective. There was no significant association between the demographic variables with pre and post test knowledge scores.

\section{Implications:}

\section{Nursing Service:}

1. Continuing Nursing Education can be arranged for staffs working in both hospitals and maternity centre.

2. Motivate the students, nurses and health care workers to update the knowledge on various methods and approaches on preparation and management of labour.

\section{Nursing administration:}

The nurse administrator can organize in service education program regarding newer modalities of non-pharmacological measures used in all stages of labour.

\section{Nursing research:}

Nursing research can be conducted to find out the effectiveness of newer modalities used management of labour, which would help in updation of the clinical practice with evidence based approach.

\section{Recommendation:}

$>$ A comparative study can be done to determine the effectiveness on management of labour between primigravida and multigravida women.

$>$ study can be conducted to assess the knowledge regarding preparation and management of labour among students and staff nurses.
$>$ A comparative study can be done to determine the effectiveness of management of labour between rural and urban areas.

\section{References:}

1. Dutta, D.C. (2006). Textbook of Obstetrics including Perinatology and Contraception. Calcutta: New Central Book Agency.

2. Polit, F. D, \& Beck, (2008). Nursing Research - Principles and Methods. Philadelphia: J.B. Lippincott Company.

3. Hutchison J, Mahdy H, Hutchison J,(2019) Stages of Labor. StatPearls [Internet]. Treasure Island (FL): StatPearls Publishing.

4. Czech I, Fuchs P, Fuchs A, Lorek M, Tobolska-Lorek D,et al (2018) Pharmacological and Non-Pharmacological Methods of Labour Pain Relief-Establishment of Effectiveness and Comparison. Int J Environ Res PublicHealth. Dec 9;15(12). : E2792.

5. Peppe MV, Stefanello J, Infante BF, Kobayashi MT, Baraldi CO, et al (2018) Perineal Trauma in a Low-risk Maternity with High Prevalence of Upright Position during the Second Stage of Labor. Rev Bras Ginecol Obstet. Jul;40(7):379-383.

6. Abdul-Sattar Khudhur Ali S, Mirkhan Ahmed H. (2018) Effect of Change in Position and Back Massage on Pain Perception during First Stage of Labor. Pain Manag Nurs. Jun;19(3):288294.

7. Solnes Miltenburg A, Kiritta RF, Meguid T, Sundby J (2018) Quality of care during childbirth in Tanzania: identification of areas that need improvement. Reprod Health. Jan 27;15(1):14.

8. Djakovic I, Djakovic Z, Bilić N, Košec V. (2015) Third Stage of Labor and Acupuncture. Med Acupunct. Feb 1;27(1):10-13.

9. Nasir A, Korejo R, Noorani KJ. (2007) Child birth in squatting position. J Pak Med Assoc. Jan;57(1):19-22. 